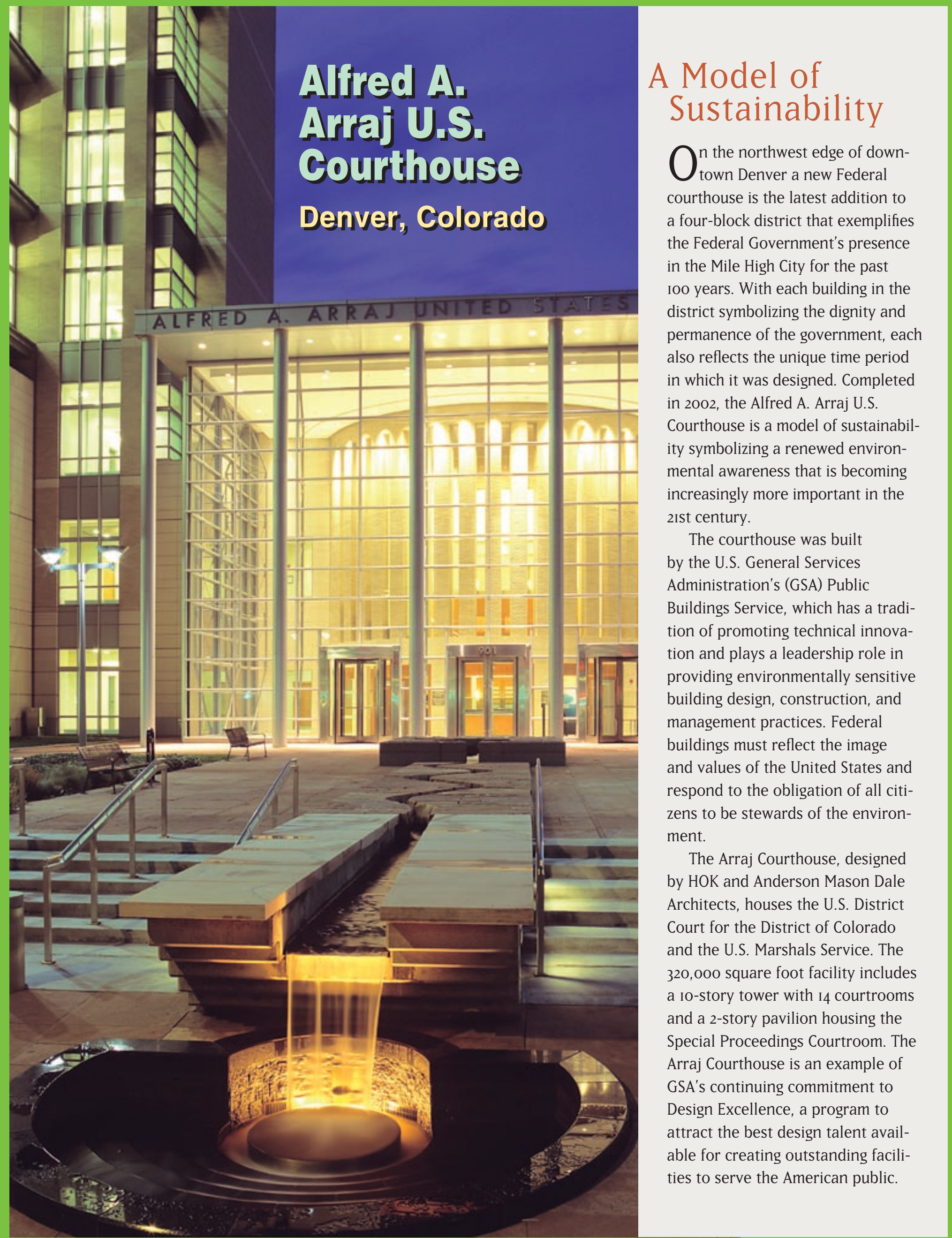




\section{Site Selection and Orientation}

The building completes a four-block Federal district delineated by 18 th and 2oth Streets and Curtis and California Streets. It is adjacent to Denver's rapid transit system and multiple bus stops to enable public transportation access. A collaborative effort between GSA, Denver and public groups made this building compatible with development objectives for the central business district. The building meets the Judiciary's current space requirements allowing for future expansion needs and is designed for a Ioo-year life expectancy.

\section{Landscape Features}

The 2-story pavilion with the public entrance and Special Proceedings Courtroom is positioned on a southeast-oriented landscaped plaza and recalls a historic courthouse-in-the-square. The plaza paving of local stone is set in sand beds rather than concrete to absorb water and help control runoff. The plaza contains a xeriscape of hardy regional plants that are low maintenance and drought tolerant. A water feature runs from the sidewalk to the building entrance symbolizing nearby streams of the high desert.

\section{Materials}

Carefully selected building materials maximize the benefits of durability, local production, recycled-content and certified wood. Interior floors of Spanish limestone are light in color and durable. Local materials include exterior stone paving and pre-cast concrete elements. All paints and adhesives are low in volatile organic compounds and water-based. Steel and other recycled content products comply with the Comprehensive Procurement Guidelines for Federal agencies. Maple wood paneling from sustainably managed forests in Pennsylvania is used throughout the courtrooms and lobby. The courtroom flooring is cork, which is a renewable natural resource traditionally used in courtrooms in the 1920's and 30's.

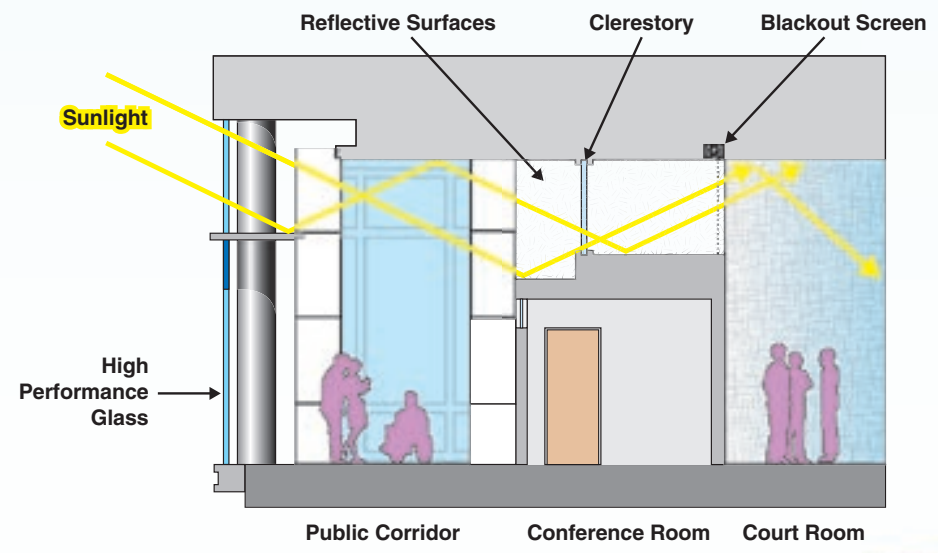

\section{Daylighting}

The public corridors of the building are oriented to the southeast to maximize solar exposure. Oversized windows provide visitors with a connection to the outdoors and magnificent views of downtown Denver. Internal light shelves bounce daylight onto light-colored surfaces so that it reaches deep into the interior. Fluted glass panels bring diffused daylight into the interior courtrooms and other spaces. Automated shades can provide $50 \%$ or $100 \%$ opacity when needed. Overall, natural light is available throughout $75 \%$ of the building.

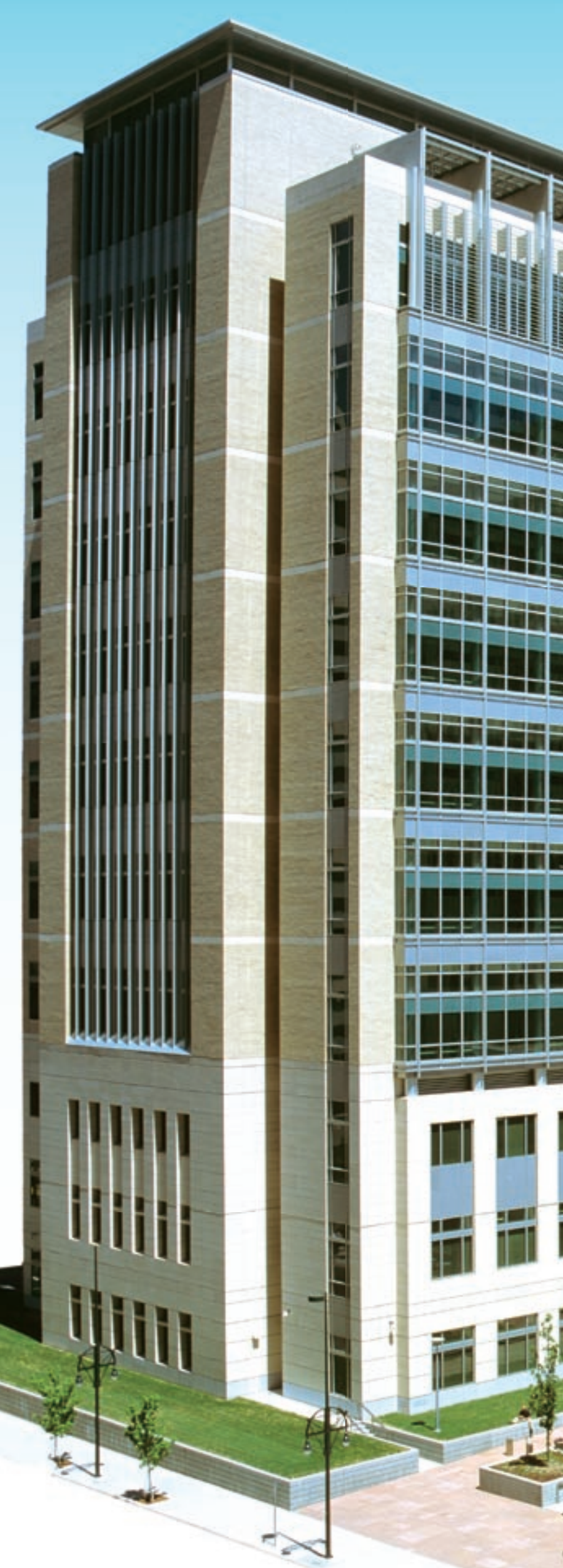




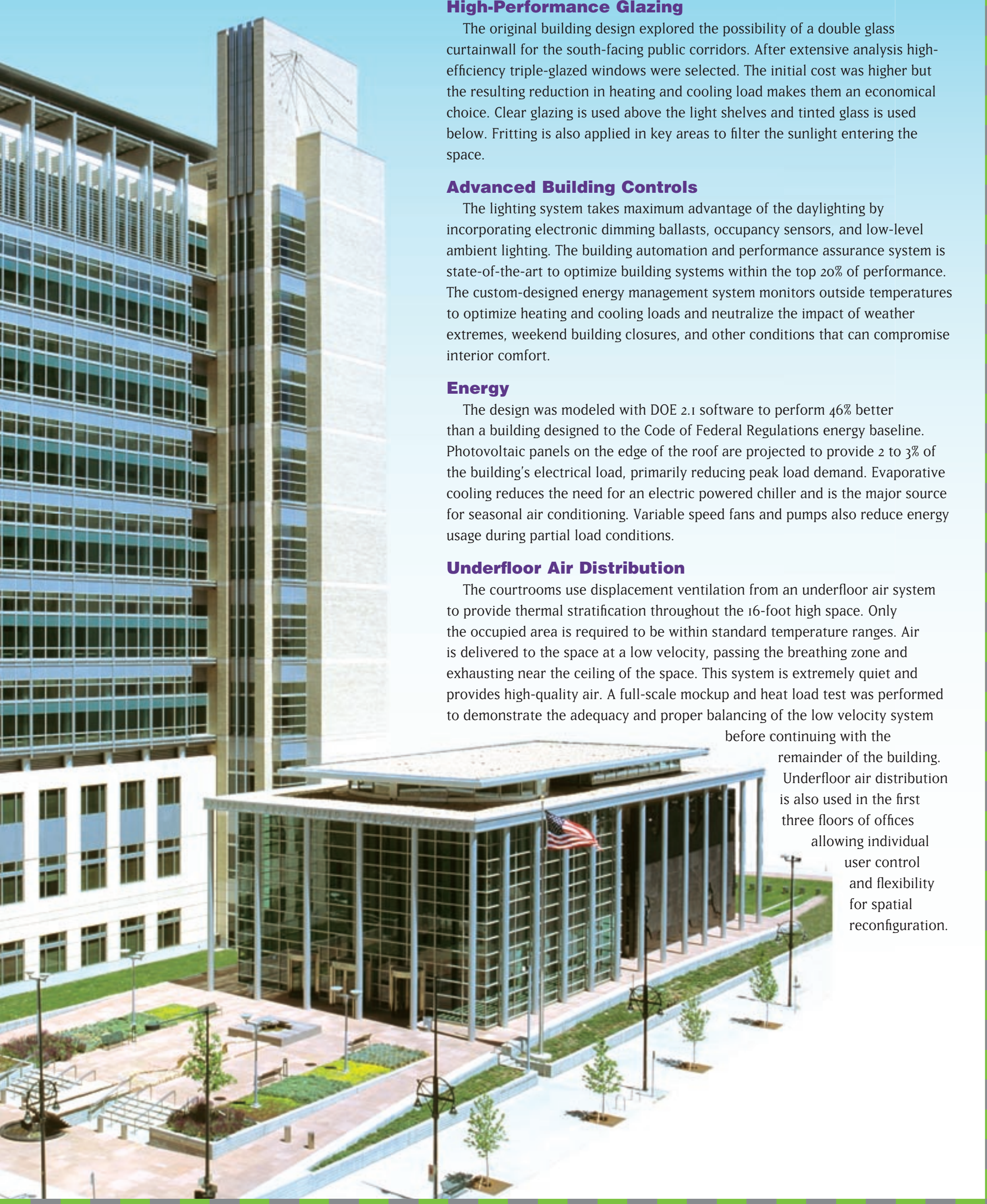




\section{GSA's Public Buildings Service}

The mission of GSA's Public Buildings Service (PBS) is to provide a superior workplace for the Federal worker and superior value to the American taxpayer. The vision is to be the best real estate organization in the world.

PBS is the landlord of the civilian Federal Government, with a total inventory of over 339 million square feet of workspace for one million Federal employees in 2,000 American communities. This includes over 1,600 government-owned buildings, or approximately 55 percent of GSA's total inventory. The remaining 45 percent is in privately owned leased facilities.

GSA is committed to incorporating principles of sustainable design and energy efficiency into all of its building projects.

As a means of evaluating and measuring its green building achievements, GSA requires all new construction projects and substantial renovations to be certified through the U.S. Green Building Council's Leadership in Energy and Environmental Design (LEED ${ }^{\circledR}$ ) rating system. Projects are encouraged to exceed basic certification and achieve the LEED ${ }^{\circledR}$ Silver Level.

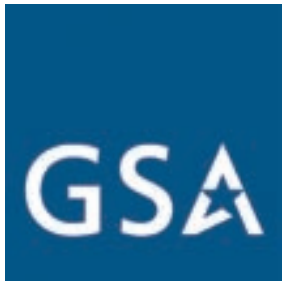

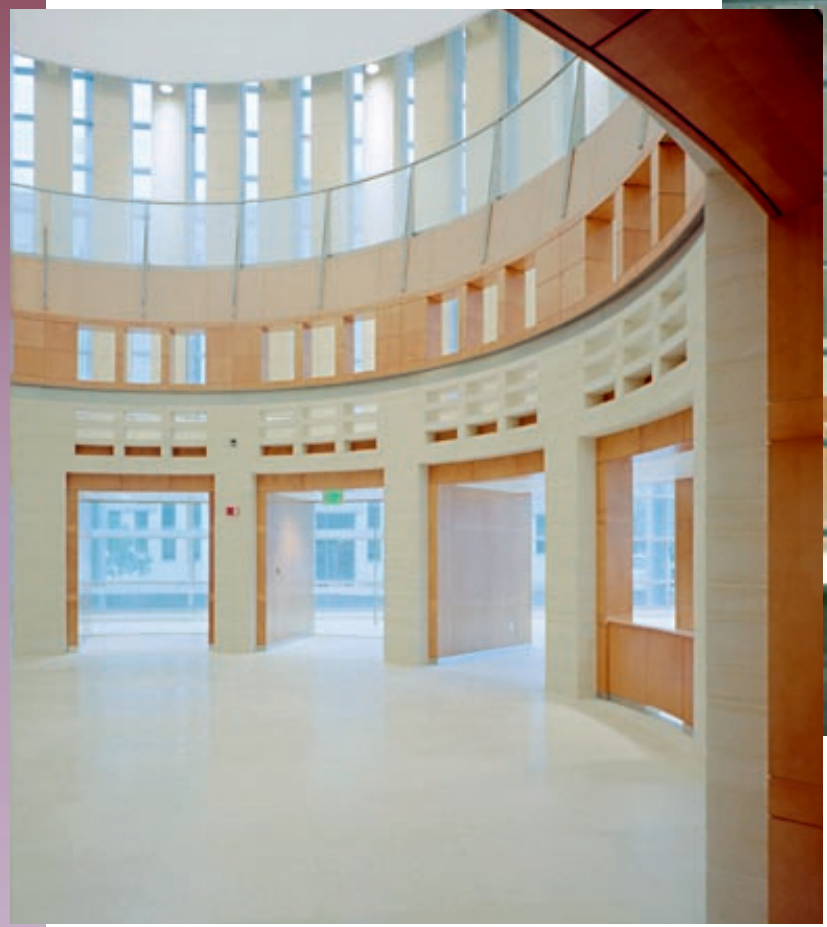

\section{A Showcase Green Courthouse}

n November of 1996 a 20-member interdisciplinary panel of leading architects, engineers, environmentalists, planners and research scientists met to recommend green building technologies for GSA's multi-billion dollar courthouse construction program. The result was guidance for incorporating green building design objectives in a Denver courthouse expansion project, later to be known as the Alfred A. Arraj U.S. Courthouse. The project team then determined which sustainable design concepts were appropriate for the project, drawing upon a study that assessed the potential costs of incorporating each strategy. First costs and life-cycle costs were considered as well as intangible benefits such as improved workplace environment, productivity, flexibility, maintainability, and occupant health and safety. Throughout the project the sustainable design measures were continuously evaluated for appropriateness and viability. After an initial budget increase of nearly $7 \%$, most sustainable features were retained through construction cost increases, value engineering and programmatic changes. GSA is proud to showcase its first green courthouse, a model of sustainability.

\section{Project Goals:}

Reduce electrical demand by $50 \%$

Provide daylighting to all building occupants

Maximize reusable products

Maximize flexibility to accommodate change

Minimize construction waste

Provide a healthy and productive work environment

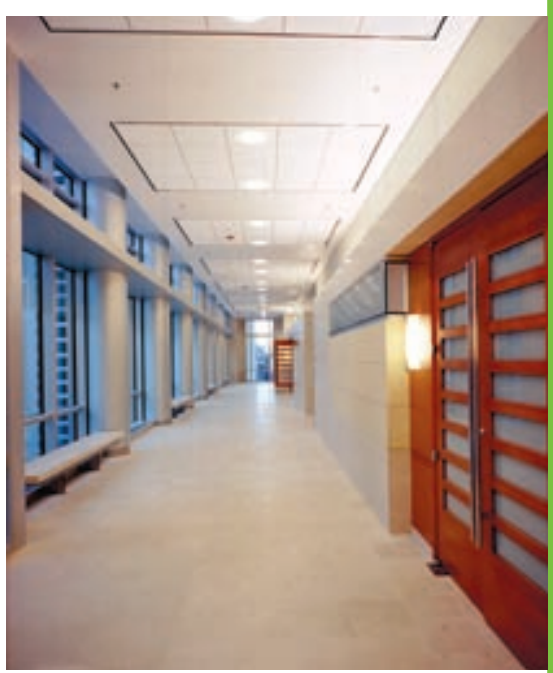

Contacts

U.S. General Services Administration Public Buildings Service

Office of Applied Science

1800 F Street, NW

Washington, DC 20405

www.gsa.gov/sustainabledesign www.highperformancebuildings.gov

U.S. General Services Administration Rocky Mountain Region

W. 6th Avenue and Kipling Street Lakewood, CO 80225

Photo Credits

(C) Frank Oms Photographer

Produced for the U.S. General Services Administration by the National Renewable Energy Laboratory, a DOE national laboratory

September 2005

Printed with a renewable-source ink on paper containing at least $50 \%$ wastepaper, including $20 \%$ postconsumer waste 